\section{Accreditation of diagnostic imaging services in developing countries}

\author{
Pablo Jiménez, ${ }^{1}$ Cari Borrás, ${ }^{2}$ \\ and Ileana Fleitas ${ }^{1}$
}

Suggested citation: Jiménez P, Borrás C, Fleitas I. Accreditation of diagnostic imaging services in developing countries. Rev Panam Salud Publica. 2006; 20(2/3):104-12.

\section{SYNOPSIS}

In recent decades, medical imaging has experienced a technological revolution. After conducting several surveys to assess the quality and safety of diagnostic imaging services in Latin America and the Caribbean, the Pan American Health Organization (PAHO) developed a basic accreditation program that can be implemented by the ministry of health of any developing country. Patterned after the American College of Radiology's accreditation program, the $P A H O$ program relies on a national accreditation committee to establish and maintain accreditation standards. The process involves a peer review evaluation of: (1) imaging and processing equipment, (2) physician and technologist staff qualifications, (3) quality control and quality assurance programs, and (4) image quality and, where applicable, radiation dose. Public and private conventional radiography/ fluoroscopy, mammography, and ultrasound services may request accreditation. The radiography/fluoroscopy accreditation program has three modules from which to choose: chest radiography, general radiography, and fluoroscopy. The national accreditation committee verifies compliance with the standards. On behalf of the ministry of health, the accreditation committee also issues a three-year accreditation certificate. As needed, the accreditation committee consults with foreign technical and clinical experts.

X-ray diagnostic examinations have been used in medicine for over a century, and they are now the most significant source of ionizing radiation in medicine around the world (1). Conventional basic and specialized diagnostic radiology, interventional radiology, and diagnostic ultrasound today play an essential role in clinical health care processes (2). These services cover a large number of clinical applications, including prenatal monitoring and the diagnosis and follow-up of respiratory disorders, fractures, digestive disorders, and breast abnormalities, as well as of more complex health problems, such as cancer, AIDS, diseases of the central nervous system, and cardiovascular diseases.

Notwithstanding the proliferation of increasingly complex X-ray technology in industrialized countries, most developing countries do not provide basic radiology services, and, whenever they do, the quality of patient care may be questionable. To reduce the inequity in the provision of imaging services around the world, since the 1970s the World Health Organization (WHO) has worked to develop criteria for equipment to provide basic radiography. 
The recommended X-ray unit is known as the World Health Imaging System for Radiography (WHIS-RAD) $(3,4)$. In the Region of the Americas, since the 1950s the Pan American Health Organization (PAHO) has addressed the problem of effectiveness and safety in radiology departments by performing national and Regionwide surveys and by implementing quality assurance and quality control programs (5-7). (The main objectives of a quality assurance (QA) program are to improve diagnostic accuracy without using unnecessary radiation, and to minimize costs. The specific tests required to ensure effective and safe equipment performance are usually referred to as quality control (QC) tests. Sometimes, the term "quality management," encompassing both QA and QC, is used.) Establishing a comprehensive quality assurance program in radiology departments that takes into account the principles established by $\mathrm{WHO}$ and $\mathrm{PAHO}$ is considered a requirement under the guidelines contained in the International Basic Safety Standards for Protection against Ionizing Radiation and for the Safety of Radiation Sources (8).

The effectiveness of diagnostic imaging services is greatly dependent on the quality of the health care provided. The existence of well-trained professionals, as well as the implementation of quality assurance programs, are essential for obtaining accurate diagnoses.

A recent PAHO assessment of imaging services in public and private hospitals in five Latin American countries revealed that very few services had implemented periodic quality control programs. The study also found that the clinical images in more than $30 \%$ of gastrointestinal tract exams and in more than $50 \%$ of lumbar spinal studies were of unacceptable quality. In the same study the accuracy of the radiological interpretation in mammography was found to depend on the experience of the physician reading the films.

Regardless of the limitations that developing countries face, they can benefit from accreditation programs if the programs are tailored to the country's specific circumstances, ${ }^{3}$ particularly the quantity and quality of human resources and the technology available in it. The customized standards should provide a real possibility for health care improvement in the specific country by addressing the needs of the community in which the imaging services are located.

The different needs of developing and industrialized countries could be met by a tiered system,

\footnotetext{
3 Jiménez $\mathrm{P}$, Borrás C, Fleitas I. Accreditation process of diagnostic imaging services in developing countries. International Federation for Medical and Biological Engineering (IFMBE) Proceedings. World Congress on Medical Physics and Biomedical Engineering; Sydney: World Congress on Medical Physics and Biomedical Engineering; 2003.
}

covering basic, intermediate, and advanced economies. This article presents a basic framework focused on less developed countries with basic economies. To this basic framework, each country could add further local legislative requirements or higher standards if required or requested.

While the clinical advantages of diagnostic imaging services are enormous, in practice these services could represent an unnecessary cost to the health care systems in the countries if the quality provided were unacceptable. An accreditation program represents a method for establishing and monitoring a set of quality standards $(9,10)$.

Although this article presents a framework based on the experience that PAHO medical physicists have acquired working in and with the countries of Latin America and the Caribbean, the proposed accreditation program could also be applied to any developing country in similar circumstances.

\section{THE PROCESS OF DEVELOPING THE ACCREDITATION PROGRAM}

Having received requests for setting standards and establishing accreditation programs in several countries, the medical physicists of PAHO'S radiological health program developed a procedure to assist ministries of health to assess, certify, and monitor accreditation programs for both public and private providers of diagnostic imaging services. The main goal was to improve diagnostic accuracy and safety.

If the ministry of health of a PAHO Member State requests guidance on establishing a diagnostic imaging accreditation program, PAHO's regional advisor on radiological health works with his or her counterparts in the $\mathrm{PAHO} / \mathrm{WHO}$ office in that country and assesses the feasibility and appropriateness of the request. That assessment takes into account the organization of health services and the role of governmental and private organizations in the authorization, accreditation, and/or certification of medical practices. Following that step the PAHO medical physicists analyze the available information on the country's diagnostic imaging infrastructure, equipment, and personnel. An expert team composed of PAHO staff members and/or PAHO consultants (including at least one radiologist and one medical physicist) is available when needed to carry out a country visit to update and document the situation regarding imaging and processing equipment performance, personnel availability and qualifications, maintenance and quality assurance program implementation, and compliance with radiation safety standards. The PAHO team members also interview public and private providers of imaging services to assess the technical 
and institutional environment in which the accreditation system is to be implemented.

This information is incorporated into the preparation of an accreditation program. The program needs to be country-specific, but it also needs to take into account the successes and failures of similar programs in industrialized countries.

\section{Reviewing different options}

To develop a basic accreditation program, the accreditation processes of different organizations need to be reviewed.

The International Organization for Standardization (ISO) is a worldwide federation of national standards agencies that is responsible for preparing international standards. It works closely with the International Electrotechnical Commission (IEC), which is the leading organization that prepares and publishes international standards for all electrical, electronic, and related technologies. ISO 9000 defines the requirements that an organization must implement in order to demonstrate the effective operation of a quality management system, irrespective of its type, size, or services provided. Compliance with this standard allows an organization to demonstrate its ability to provide a service that meets customer requirements. ISO/IEC 17025 defines both a quality management system and the technical requirements for testing and/or calibration facilities. Unlike ISO 9000 , the major emphasis of ISO/IEC 17025 is the determination of competence of personnel to produce reliable data and results for specific tests and/or procedures. ISO/IEC 17025 is a generic document that covers all testing and/or calibration types. Accreditation bodies issue guidance documents to expand and explain how the requirements, such as personnel qualifications, minimum infrastructure, and generic procedures, are applicable to any field. There have been some experiences (for example, in Australia and Spain) based on ISO/IEC 17025 with additional radiology-specific professional, technical, and administrative requirements incorporated into the relevant sections. However, there are no documented examples of such programs in developing countries.

The Joint Commission on Accreditation of Healthcare Organizations (JCAHO) is an independent nonprofit organization that evaluates and accredits more than 16000 health care organizations and programs in the United States. JCAHO's standards address a health care organization's level of performance in key functional areas such as patient rights, patient treatment, and infection control. The JCAHO standards focus both on an organization's ability to provide safe, high-quality care and on its actual performance. The standards set forth perfor- mance expectations for activities that affect the safety and quality of patient care. JCAHO develops its standards in consultation with health care experts, health care providers, measurement experts, equipment manufacturers, and consumers. Although this program is very useful for health organizations as providers, it is not considered appropriate for imaging services accreditation in developing countries. That is because JCAHO standards are oriented to organizational aspects affordable only by high-income countries rather than being focused on the diagnostic accuracy and radiation dose aspects that are essential for the quality of care provided by imaging services in lower-income countries.

The American College of Radiology (ACR), which has more than 30000 members, is the principal organization of radiologists, radiation oncologists, and clinical imaging medical physicists in the United States. The ACR is a nonprofit professional society whose primary purposes are to advance the science of radiology, improve radiological services to patients throughout the United States, study the socioeconomic aspects of the practice of radiology, and encourage continuing education for radiologists, radiation oncologists, medical physicists, and persons practicing radiology in allied professional fields.

ACR's guidelines are an educational tool designed to assist practitioners in providing appropriate radiological care for patients (11). In delivering effective and safe medical care, it is expected that the practitioner will follow a reasonable course of action that is based on current knowledge, available resources, and the needs of the patient. Although ACR's standards are designed for the United States, they can be tailored to the needs of other countries, provided adjustments are made regarding personnel qualification requirements in countries where the quantity and quality of human resources are more limited than they are in the United States.

An example of an accreditation program that the PAHO radiological health program has proposed for a Latin American or Caribbean country is presented in the next section. The proposed program is based on the ACR program. That is because the medical physicists in the PAHO radiological health program considered that of all the accreditation processes that they reviewed, the ACR program best encompassed the managerial, clinical, and technical aspects that were essential for the success of the accreditation program. Furthermore, many radiologists in Latin America and the Caribbean are members of the ACR. They are thus familiar with the ACR technical guidelines, and they try to adhere to them.

The costs involved in developing and implementing an accreditation program will depend on the number and complexity of the imaging facilities in a particular nation. Before attempting to establish 
the program, the ministry of health should prepare a careful budget and ensure program sustainability for at least five years. When trying to convince the government to provide the needed financial support, the ministry of health can provide data on erroneous diagnoses and their consequences in terms of early death, crippling morbidity, and other social and financial costs.

\section{AN EXAMPLE OF AN ACCREDITATION PROGRAM}

\section{General requirements for the accreditation process}

A typical accreditation program includes a peer review evaluation of: (1) radiography, fluoroscopy, mammography, and ultrasound imaging and processing equipment performance; (2) physician and technologist staff qualifications; (3) implementation of quality control and quality assurance programs; and (4) image quality assessment and, where applicable, radiation dose measurements. The program is implemented and monitored by a national accreditation committee established by the ministry of health. This committee is to be composed of national experts in the different disciplines involved in imaging services, but the ministry of health may also invite foreign technical and clinical experts to participate, as needed, through the technical cooperation provided by PAHO.

The accreditation committee will initiate the process by sending an application package to the facility in order to obtain information on the number and qualifications of radiologists and radiological technologists, type and extent of quality control and quality assurance programs, and such other requirements as access to the professional services of a qualified medical physicist. Detailed information will be requested on procedure workload, reporting mechanisms, number and characteristics of diagnostic imaging units, image receptors, and methods of patientimage archiving. Instructions regarding phantom and clinical image acquisition, as well as data sheets to be submitted to the accreditation committee with each image or study, will also be included. Image quality and dose assessments are an important part of the process. They will be evaluated using specially designed phantoms (optional for ultrasound) and thermoluminescent dosimeters. The facility must submit an image of the phantom and sets of normal clinical films. Both the phantom image and the clinical images will be scored by a review panel of experts appointed by the accreditation committee.

When all stages of the evaluation are completed, the accreditation committee will issue to the lead interpreting physician of the health facility a final report that includes specific assessments and recommendations. The facility's original images will be returned along with this report. Facilities that satisfy all of the criteria will be awarded a three-year accreditation certificate by the accreditation committee, on behalf of the ministry of health, and will receive a unit decal for each approved diagnostic imaging unit. For units that are added after the accreditation has been granted, the facility is required to submit technical specifications for the unit and a copy of a medical physicist's equipment evaluation report. The accreditation committee will then request additional testing materials from the new unit. If a diagnostic modality is added to any unit, the facility is also required to notify the accreditation committee, and additional images may be required from that unit.

When facilities do not meet the accreditation criteria, the committee will make specific recommendations for improvements. These recommendations provide guidance so that a facility can meet the criteria after corrective action and reapplication. A facility that fails to satisfy the image evaluation criteria will only be required to resubmit those items that were deficient, e.g., phantom images or clinical images.

To verify that accredited facilities maintain consistent quality during the three-year accreditation period, random on-site surveys and random mail-in film checks may also be performed at any time during the accreditation period. These spot checks offer an excellent opportunity for a positive educational exchange with experts in the field. They also provide validation of the submitted information. Any facility chosen for an on-site survey will be notified in advance. The survey team will be appointed by the accreditation committee. During this survey, the site visit team will review the quality assurance program, review policies and procedures, review personnel qualifications, review the facility's clinical images and reports, and work with the facility's staff to acquire and evaluate a phantom image, along with a dose assessment of the X-ray unit.

To be eligible for accreditation, all of the facility's imaging units covered by this accreditation program must meet the performance and specification criteria included in the applicable standards of the IEC and the ISO, or the equivalent national standards. Facilities must also comply with the requirements of the International Basic Safety Standards for Protection against Ionizing Radiation and for the Safety of Radiation Sources (8).

A quality assurance (QA) program should be in place. As stated by the WHO (2), quality assurance in diagnostic radiology is: "All those planned and systematic actions necessary to provide adequate confidence that a structure, system, or com- 
Qualifications for physicians. To specifically address the need for high-quality radiology, the physicians supervising and/or interpreting conventional radiological examinations shall be required to meet all the following minimum criteria:

1. Shall be licensed to practice medicine, and either: (a) be certified in radiology or diagnostic radiology by a national medical board (usually established by the ministry of health), and be approved by the accreditation committee or (b) shall have a minimum of six months of documented formal dedicated training in the interpretation and formal reporting of at least 1000 general radiographs, including patients of all ages, in a residency program approved by the accreditation committee; the program should include specific radiographic training pertinent to all body areas of which the physicians intend to interpret radiographic studies.

2. Shall have documented training in the physics of diagnostic radiography with respect to the equipment needed to safely produce such images. This should encompass physical principles of general radiography, film-screen combinations, conventional image processing, and, where applicable, digital image processing.

3. Shall have documented training in the principles of radiation protection, including instruction in radiation monitoring requirements and the hazards of radiation exposure for both patients and radiological personnel.

4. Shall have an understanding of other medical imaging modalities (fluoroscopy, computed tomography, ultrasound, magnetic resonance imaging, nuclear medicine, etc.) and their value relative to general radiography in order to best evaluate the patient's clinical symptoms.

5. If interpreting chest radiographs (and/or pediatric chest radiographs), shall have a minimum of three months documented formal training in the interpretation and formal reporting of chest radiography (and/or pediatric radiology) in a residency program approved by the accreditation committee. Such training may have taken place during the six months of other instruction in general radiography.

6. If performing and/or interpreting fluoroscopic radiographs, shall have a minimum of six months documented formal training in the interpretation and formal reporting of fluoroscopic procedures (noninvasive chest and gastrointestinal contrast studies) in a residency program approved by the accreditation committee. The program should include specific gastrointestinal training. Such training may have taken place during the six months of other instruction in general radiography.
A minimum of 200 radiographic examinations per year is recommended in order to maintain an appropriate level of expertise. If the facility performs fluoroscopy (noninvasive chest and gastrointestinal contrast studies), the performance of a minimum of 50 fluoroscopic examinations per year per physician is recommended, but not required, in order to maintain an appropriate level of expertise. If the accreditation committee finds that there are too few examinations to fulfill these recommendations, the committee will assess the situation, and may deny accreditation.

Qualifications for the radiographer or radiological technologist. The radiographer or radiological technologist must possess a degree from a program approved by the accreditation committee. The program should include a minimum of 2000 hours of experience. It is recommended that the radiographer or radiological technologist participate in continuing education activities that include general radiography and quality control on a periodic basis, the frequency of which is to be determined by the complexity of the imaging exams to be performed.

Quality control. For the radiography/fluoroscopy portion of the accreditation program, each health care facility is required to submit documentation on what quality control tests are being performed, and their frequency. Table 1 shows recommended quality control tests and the minimum frequencies for them. A medical physicist must test the unit's performance at installation and at least annually thereafter.

To assess the technical performance under clinical situations of all equipment to which this accreditation program applies, the Radiography/ Fluoroscopy Accreditation Phantom from the ACR is recommended.

Clinical images. It is not necessary to submit clinical images from every fixed radiographic unit, although phantom images must be taken from every radiographic unit. However, the radiographic unit that performs a particular imaging study most frequently should be the one from which clinical images are obtained. Sites cannot submit images performed on models or volunteers. The images to be submitted once per facility are shown in Table 2.

\section{Specific requirements for mammography}

The accreditation committee requires that a lead interpreting physician be identified by the mammography facility. Screening mammography may be performed without a physician in attendance. The accreditation committee may decide 
TABLE 2. Clinical images needed to be submitted to the accreditation committee in order to obtain accreditation for radiography/fluoroscopy modalities

\begin{tabular}{lll}
\hline \multicolumn{1}{c}{ Chest module } & General radiography module & Fluoroscopy module \\
\hline - $\mathrm{PA}^{\mathrm{a}}$ and lateral chest on small patient & $\begin{array}{l}\text { - One elbow exam } \\
\text { - One abdomen exam }(\mathrm{AP} \geq 25 \mathrm{~cm})\end{array}$ & $\begin{array}{l}\text { O One double-contrast barium enema } \\
\text { OR (for pediatric-only facilities) one } \\
\text { single-contrast barium enema }\end{array}$ \\
$\begin{array}{l}\text { - } \mathrm{PA} \text { and lateral chest on large patient } \\
(\mathrm{AP} \geq 23 \mathrm{~cm})\end{array}$ & $\begin{array}{l}\text { - One cervical-spine exam } \\
\end{array}$ & \\
\hline a $\mathrm{PA}=$ posteroanterior. & & \\
${ }^{\mathrm{A}} \mathrm{AP}=$ anteroposterior. &
\end{tabular}

that adequate supervision can be maintained in offsite facilities through professional feedback, at least quarterly, by physicians qualified in mammography. Review should include clinical image quality and quality assurance procedures, all quality control documentation, and a determination that safe operating procedures are used. The facility should maintain a log of these activities, signed by the radiologist. The accreditation committee may ask to review this $\log$ at any time.

Each facility must establish and maintain a mammography medical outcomes audit program to follow up positive mammography assessments and to correlate pathology results with the interpreting physician's findings.

Physician qualifications. To specifically address the need for high-quality mammography, the physicians supervising and/or interpreting mammograms shall be required to meet all of the following minimum criteria:

1. Shall be licensed to practice medicine, and either: (a) be certified in radiology or diagnostic radiology by a national medical board (usually established by the ministry of health), and be approved by the accreditation committee, or (b) shall have at least three months documented training in mammography interpretation, radiation physics, radiation effects, and radiation protection.

2. Have 40 hours of training in mammography, at least 15 of which must have been acquired in the three years immediately prior to the physician's practicing mammography.

3. Have interpreted mammograms from exams of 100 patients within the 12 months immediately prior to the physician's qualifying date for mammography.

4. Have received at least eight hours of training in any new mammographic modality for which the interpreting physician has not been trained, before he/she can begin using that modality.

Technologist qualifications. The radiographer or the radiological technologist must possess a degree from a program approved by the accreditation committee and have at least 40 hours of documented training in mammography, including:

1. training in breast anatomy and physiology, positioning and compression, quality assurance/ quality control techniques, and imaging of patients with breast implants

2. performance of a minimum of 25 mammography examinations under direct supervision of an appropriate qualified individual

3. at least 8 hours of training in using a mammographic modality before beginning to use that modality independently

It is recommended that continuing education activities be performed that include mammography exams and quality control.

Quality control. A medical physicist must perform an equipment evaluation of the mammography unit and film processor at installation, and write a complete report at least annually. In addition, a medical physicist must conduct an equipment evaluation when a unit or processor is disassembled and reassembled at the same or a new location, or after major components are changed or repaired. All problems must be corrected before the new or changed equipment is put into service for examinations or film processing.

Mammography quality control tests and their minimum frequency are given in Table 3 (12).

Clinical images. The facility must submit two sets of negative clinical images (one from a patient with fatty breasts and one from a patient with dense breasts), which will be scored by a review panel of experts in mammography interpretation appointed by the accreditation committee. Each set of four clinical images must consist of a craniocaudal view and a mediolateral oblique view of each of the breasts. The parameters that will be scored on the clinical images include positioning, compression, exposure level, sharpness, contrast, noise, exam identification, and artifacts. Clinical images should be examples of the facility's best work, and they will be judged accordingly by the review panel. 
TABLE 3. Mammography quality control tests and their minimum frequency

\begin{tabular}{lc}
\hline \multicolumn{1}{c}{ Test } & Minimum \\
frequency
\end{tabular}

\section{Specific requirements for ultrasound}

The ultrasound accreditation program has four modules from which to choose: (1) obstetrical, (2) gynecological, (3) vascular, and (4) general. The general module includes upper abdominal ultrasound, female pelvis ultrasound, renal/urinary ultrasound, small parts, transrectal/prostate ultrasound, and pediatric neurosonology. A facility may apply for all four modules or for any combination of them.

Each facility seeking accreditation of ultrasound services should submit clinical images and physicians' reports to the accreditation committee. In addition, for each unit, a summary of an annual performance evaluation test should be enclosed. This summary should document the results from testing the transducers that are used for the most frequent examination(s) at the facility.

Physician reports are requested for all examinations in order to confirm the date of examination and the type of examination performed. For vascular work, where appropriate, the reports must contain results from noninvasive pressure testing, obtained either from the referral source or from actual testing performed at the site of prac- tice. It is desirable for normal lab values for velocity measurements to appear at the bottom of reports, as a reference; this is especially helpful with carotid examinations.

Personnel qualifications. The physicians supervising and/or interpreting ultrasound examinations shall be required to show evidence of training in ultrasound in a program approved by the accreditation committee. Sonographers should be certified by a program approved by the accreditation committee. Continuing educational activities are recommended for both the physician and the sonographer.

Quality control. Routine quality control (QC) testing of the ultrasound equipment must occur regularly; a minimum requirement is annually. The same tests must be performed during each testing period so that changes can be monitored over time, and effective corrective actions taken.

For ultrasound units operating in gray-scale imaging mode, the QC program must evaluate at least the following parameters: system sensitivity and/or penetration capability, image uniformity, photography and other hard-copy recording, and assurance of electrical and mechanical safety. A low-contrast object detectability test is optional. These parameters may be assessed using commercially available phantoms. Using a phantom test object will be helpful in responding to questions about low-contrast detectability in the quality control part of the application. However, the use of a phantom test object is optional. In addition, it is recommended that users verify vertical and horizontal distance measurement accuracy when a QC program for an ultrasound unit is initiated.

On an ongoing basis, tests should be done using two probes commonly used with any unit employing more than one transducer. It is recommended that the transducers be of different scan types. One can be a linear (or curvilinear) array, and the other a sector (mechanical, phased, or vector) transducer.

Clinical images. Original ultrasound films (transparencies only) or near-original-quality copies will be accepted. Normal examinations are requested. For vascular exams, both normal and abnormal exams are required. Diagnostic physiologic and anatomic findings (especially for examinations containing abnormal findings) must be contained in the accompanying physician report. All views of an ultrasound examination must be from an examination performed on the same patient.

Clinical images will be evaluated on an objective scoring system approved by the accreditation committee. 


\section{CONCLUSIONS}

In recent decades, medical imaging has experienced a technological revolution. Steady advances in the quality of radiological images and in patient protection have ensured a continuing role for the use of diagnostic $X$ rays in health care. While clinical audits will play an increasingly important role in the control of imaging services, it is the responsibility of governments to attest to the effectiveness and quality of the services. Authorities and consumers are likely to be more receptive to a minimum set of standards developed by an independent international organization than they would be to requirements set by national regulatory bodies. Standard processes, such as training, documentation, and problem-solving, must be adopted. The introduction of external experts into the radiology department is an informal type of benchmarking. The major benefit of an accreditation process is that a review of work practices must occur. Improvements will inevitably flow from this review.

All of the following activities are highly recommended: accreditation under formal quality systems and audits of practice; the training and education of persons involved with medical radiation, including physicians, technologists, medical physicists, and administrators; the promulgation of basic recommendations on patient protection; and guidance on the rational and effective use of imaging. Both public and private medical imaging centers in developing countries will benefit from such an accreditation process.

\section{SINOPSIS}

\section{La acreditación de los servicios de imaginología médica en países en desarrollo}

En los últimos decenios, la imaginología médica ha sufrido una revolución tecnológica. Después de realizar varios estudios para determinar la calidad y la seguridad de los servicios de imaginología diagnóstica en América Latina y el Caribe, la Organización Panamericana de la Salud (OPS) creó un programa básico de acreditación para servicios de imaginología que las autoridades de salud de cualquier país en desarrollo pueden poner en práctica. Diseñado a partir del programa de acreditación del Colegio Estadounidense de Radiología (American College of Radiology), el de la OPS se apoya en comités internacionales de acreditación para establecer y mantener determinadas normas. Con esta finalidad se lleva a cabo una evaluación por pares de: 1) el equipo radiológico y el de procesamiento de la imagen; 2) la calificación del personal médico y técnico; 3) los programas de control y garantía de la calidad; 4) la calidad de la imagen y, cuando procede, 5) la dosis de radiación. Los servicios públicos y privados de radiografía y fluoroscopia, mamografía y ecografía pueden solicitar su acreditación. El programa de acreditación de los servicios de radiografía y fluoroscopia ofrece tres módulos, entre los cuales se puede elegir: radiografía de tórax, radiografía general y fluoroscopia. El comité internacional de acreditación se cerciora de que se hayan cumplido las normas vigentes y extiende, a nombre del ministerio de salud, un certificado de acreditación válido por tres años. Cuando es necesario, dicho comité consulta a expertos extranjeros, que pueden ser del ámbito clínico o técnico.

Palabras clave: diagnóstico por imagen, radiología, acreditación, países en desarrollo, América Latina, región del Caribe.

\section{REFERENCES}

1. United Nations Scientific Committee on the Effects of Atomic Radiation. Sources and effects of ionizing radiation. UNSCEAR 2000 report to the General Assembly, with scientific annexes. Vienna: UNSCEAR; 2000.

2. Pan American Health Organization. Organization, development, quality assurance and radiation protection in radiology services: imaging and radiation therapy. Washington, D.C.: PAHO; 1997.

3. World Health Organization. WHISRAD high sophistication in a marvel of simplicity. Geneva: WHO; 2004.

4. World Health Organization. Consumer guide for the purchase of $\mathrm{X}$-ray equipment. Geneva: WHO; 2000. (WHO/ DIL/00.1 Rev. 1).

5. Pan American Health Organization. Promoting health in the Americas: annual report of the Director-2001. Washington, D.C.: PAHO; 2001.
6. Pan American Health Organization. Health in the Americas: 1998 edition. Washington, D.C.: PAHO; 1998. (Scientific Publication 569).

7. Pan American Health Organization. Health in the Americas: 2002 edition. Washington, D.C.: PAHO; 2002. (Scientific and Technical Publication 587).

8. Food and Agriculture Organization of the United Nations, International Atomic Energy Agency, International Labour Organisation, Nuclear Energy Agency of the Organisation for Economic Co-operation and Development, Pan American Health Organization, World Health Organization. International basic safety standards for protection against ionizing radiation and for the safety of radiation sources. Vienna: IAEA; 1997. (Safety series 115).

9. International Commission on Radiological Protection. Protection against ioniz- ing radiation from external sources used in medicine. Oxford: ICRP; 1982. (Publication 33).

10. International Commission on Radiological Protection. Protection of the patient in diagnostic radiology. Oxford: ICRP; 1982. (Publication 34).

11. American College of Radiology. Accreditation. Available from: http://www. acr.org/s_acr/sec.asp?CID=2541\&DID $=17586$ [Web site]. Accessed 18 August 2005.

12. American College of Radiology. Mammography quality control manual. Reston: ACR; 1999.

Manuscript received on 14 December 2004. Revised version accepted for publication on $30 \mathrm{Au}$ gust 2005. 